
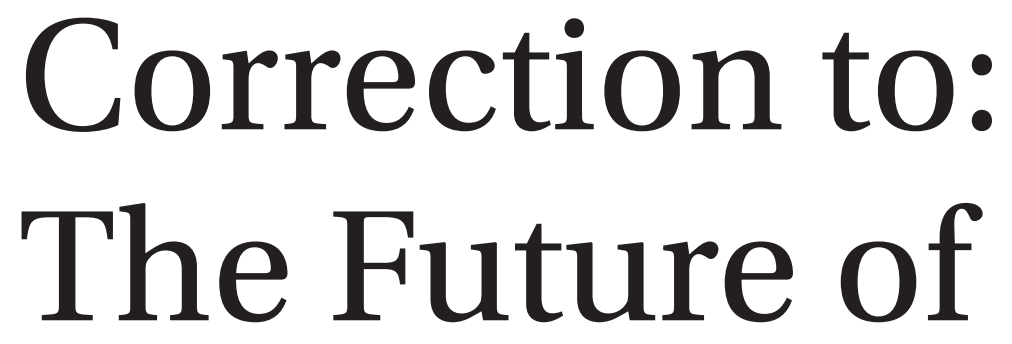

\title{
the Workplace
}

\section{Bill Fox}

\section{Correction to:}

B. Fox, The Future of the Workplace https://doi.org/ / 0.1 007/978- I-4842-5098-3

The book was inadvertently published with an incorrect title for all chapters and it has been updated. The chapter titles were given as two parts in different font sizes (example: Norman Bodek Owner, PCS Press) and hence, the first part Norman Bodek was taken as title and the rest, Owner, PCS Press was considered as sub title. This has occurred in all the chapters and all of which have been corrected.

The updated online version of this book can be found at https://doi.org/10.1007/978-1-4842-5098-3

(C) Bill Fox 2020

B. Fox, The Future of the Workplace, https://doi.org/I0.1007/978-I-4842-5098-3_3I 